\title{
Resíduos de azevém na superfície de um Planossolo alagado e seus efeitos na concentração de nutrientes na solução do solo e em plantas de arroz
}

\author{
Ryegrass residues on soil surface of a flooded Albaqualf soil and their effects on nutrients \\ concentration in soil solution and rice plants
}

\author{
Fábiana Schmidt ${ }^{\mathrm{I}}$ Rogério Oliveira de Sousa' ${ }^{\mathrm{II}}$ Magali de Ávila Fortes ${ }^{\mathrm{I}}$ \\ Roberto Carlos Doring Wolter ${ }^{\mathrm{I}}$ Jonas Wesz $^{\mathrm{III}}$
}

\section{RESUMO}

A incorporação de resíduos de culturas ao solo em lavouras de arroz irrigado tem o potencial de melhorar as características físicas, químicas e biológicas do solo e acelerar as reações de oxirredução durante o alagamento, proporcionando maior disponibilidade de nutrientes para as plantas, que respondem com maior crescimento e maior absorção de nutrientes. Com o objetivo de determinar a concentração de nutrientes na solução do solo e quantificar a absorção de nutrientes e o crescimento de plantas de arroz submetidas a quantidades crescentes de resíduos de azevém aplicadas na superfície do solo, foi conduzido um experimento em casa de vegetação. $O$ experimento foi delineado em blocos ao acaso, com três repetições, sendo utilizadas como tratamentos doses de resíduos de azevém $(0,0 ; 1,25 ; 2,5 ; 5,0$; 7,5 e 10,0Mg ha-1) aplicadas na superfície de um Planossolo. Sementes de arroz pré-germinadas da cultivar 'BRS 7 Taim' foram semeadas na superfície do solo, que foi alagado 15 dias após, e as plantas foram cultivadas por um período de 45 dias. Nas plantas de arroz, foram avaliados a massa seca da parte aérea e os teores dos nutrientes: $\mathrm{N}, \mathrm{K}, \mathrm{P}, \mathrm{Ca}, \mathrm{Mg}, \mathrm{Fe}, \mathrm{Mn}, \mathrm{Cu} e$ $\mathrm{Zn}$. Na solução do solo, foram avaliados o potencial redox (Eh), o pH e as concentrações de $\mathrm{Mn}, \mathrm{Fe}, \mathrm{K}, \mathrm{Ca}$ e $\mathrm{Mg}$. Os resultados mostraram que a adição de doses crescentes de resíduos de azevém na superfície do solo alagado, até a dose máxima de $10 \mathrm{Mg} \mathrm{ha}{ }^{-1}$, intensificou o processo de oxirredução do solo, aumentando a concentração de $\mathrm{Mn}, \mathrm{Fe}, \mathrm{Ca}, \mathrm{Mg}$ e K na solução do solo, aumentou os teores de $\mathrm{K}$ e Fe na parte aérea das plantas de arroz e aumentou a massa seca de arroz.

Palavras-chave: oxirredução, disponibilidade de nutrientes, resíduos vegetais.

\section{ABSTRACT}

The incorporation of ryegrass residues on the soil in rice irrigated fields can improve the physical, chemical and biological soil properties. It can also accelerate the redox reaction during the soil flooding, allowing a higher availability of nutrients to the plants, which responds with a higher growing and nutrient absorptions. The objectives of this research are to quantify the nutrient absorptions, the rice crop growing, and to determine the concentration of nutrients in the soil solution on a flooding Albaqualf soil. For this, increasing doses of ryegrass residues were applied in the soil surface. A greenhouse experiment was carried out using a randomized complete block design with six doses of ryegrass residues $(0.0 ; 1.25 ; 2.5$; 5.0; 7.5 and $10.0 \mathrm{Mg} \mathrm{ha}^{-1}$ ) applied to the soil surface. Cultivar 'BRS 7 Taim' pre-germinated seeds were sown in plastic pots. The soil in the pots was flooded 15 days after this procedure and plants were hept in this condition for an additional 45 days. In the rice plants were evaluated the dry matter weight of the shoots and the following nutrients: $\mathrm{N}, \mathrm{K}, \mathrm{P}, \mathrm{Ca}, \mathrm{Mg}, \mathrm{Fe}, \mathrm{Mn}, \mathrm{Cu}$ and $\mathrm{Zn}$. In the soil solution were evaluated the redox potential (Eh), $\mathrm{pH}$, and the concentration of $\mathrm{Mn}, \mathrm{Fe}, \mathrm{K}, \mathrm{Ca}, \mathrm{Mg}$. Results show that the addition of increasing doses of ryegrass residues in the flooded soil surface until $10 \mathrm{Mg} \mathrm{ha}{ }^{-1}$ strengthened the soil redox reaction process increasing the concentration of $\mathrm{Mn}, \mathrm{Fe}$, $\mathrm{Ca}, \mathrm{Mg}$ and $\mathrm{K}$ in the soil solution. It also increased the $\mathrm{K}$ and $\mathrm{Fe}$ contents in the aerial part of rice plants as well increased their dry matter weight.

Key words: redox reaction, availability of nutrients, organic residues.

\section{INTRODUÇÃO}

A incorporação de resíduos orgânicos ao solo, em lavouras de arroz irrigado, melhora as características físicas, químicas e biológicas do solo, contribuindo para diminuir a degradação dos solos de

'Programa de Pós-graduação em Agronomia/Solos, Universidade Federal de Pelotas (UFPEL), Pelotas, RS, Brasil.

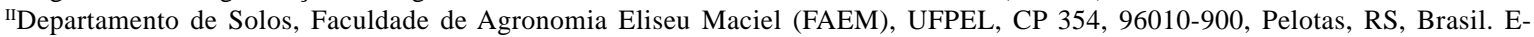
mail: rogério.sousa@pq.cnpq.br. Autor para correspondência.

${ }^{\text {IIIC }}$ urso de graduação em Agronomia, FAEM, UFPEL, Pelotas, RS, Brasil. 
várzea pelos sucessivos cultivos do arroz. Nem sempre são observados aumentos expressivos de rendimento; no entanto, a incorporação de resíduos orgânicos é de fundamental importância para manter os rendimentos altos e estáveis ao longo dos cultivos (SINGH et al., 1991). Além disso, resíduos orgânicos facilmente decomponíveis são excelentes fontes de carbono e energia aos microorganismos anaeróbios, acelerando as reações de oxirredução e acentuando as transformações químicas em um solo alagado (GAO et al., 2004), proporcionando maior disponibilidade de nutrientes às plantas, que respondem com maior crescimento e produtividade (SINGH et al., 1991).

No entanto, a adição de resíduos vegetais em solos alagados apresenta dois efeitos antagônicos: por um lado, pode favorecer o crescimento das plantas, devido à maior quantidade de nutrientes que proporciona, por outro lado, pode restringir o crescimento pela produção de substâncias tóxicas decorrentes da fermentação e devido à imobilização do nitrogênio. Dentre os fatores que contribuem para que ocorra uma ou outra situação, destaca-se a quantidade de resíduo, que determina a maior ou menor disponibilidade de carbono para os microorganismos anaeróbios (SOUSA, 2001).

A prática de incorporação de resíduos orgânicos ao solo não é muito utilizada nas lavouras comerciais de arroz irrigado do Estado do Rio Grande do Sul. Atualmente, o sistema de preparo convencional do solo está sendo substituído paulatinamente pelos sistemas de cultivo mínimo ou plantio direto, que juntos atingiram $67 \%$ da área total cultivada com arroz na safra 2004/05 (IRGA, 2006). O plantio direto, particularmente, é realizado integrado com a pecuária pelo aproveitamento de pastagens de inverno nas áreas, antes do cultivo do arroz (GOMES et al., 2004).

Observações realizadas em lavouras comerciais de arroz irrigado, em plantio direto, têm indicado que não se devem utilizar quantidades de resíduos vegetais superiores a $4 \mathrm{Mg} \mathrm{ha}^{-1}$. Por outro lado, em diversos experimentos que confrontaram os rendimentos do arroz irrigado no sistema convencional e plantio direto, não foram observadas diferenças significativas entre tratamentos em que o peso da matéria seca das espécies de inverno variou de 1 a $6 \mathrm{Mg} \mathrm{ha}^{-1}$ (MENEZES et al., 1997). Quantidades entre 2 e $8 \mathrm{Mg} \mathrm{ha}{ }^{-1}$ de resíduos de azevém são consideradas ideais para que o arroz responda com maior rendimento de grãos (SINGH et al., 1991).

Nesse contexto, o estudo foi realizado com os objetivos de determinar a concentração de nutrientes na solução do solo e quantificar a absorção de nutrientes e o crescimento de plantas de arroz submetidas a quantidades crescentes de resíduos de azevém aplicadas na superfície do solo.

\section{MATERIAL E MÉTODOS}

Para atingir os objetivos propostos, foi conduzido um experimento em vasos, na casa de vegetação da Faculdade de Agronomia Eliseu Maciel da Universidade Federal de Pelotas (UFPEL). Foi utilizado o solo da camada de 0 a $20 \mathrm{~cm}$ de profundidade de um Planossolo Háplico coletado no Centro Agropecuário da Palma (UFPEL), no município do Capão do Leão. O experimento foi delineado em blocos ao acaso, com três repetições, constando como tratamentos quantidades equivalentes a 0,$0 ; 1,25 ; 2,5$; 5,0; 7,5 e 10,0 $\mathrm{Mg} \mathrm{ha}^{-1}$ de resíduos de azevém aplicados na superfície do solo.

O solo previamente destorroado e peneirado em peneira de $1 \mathrm{~cm}$ de malha foi colocado em vasos plásticos de 8 litros, na quantidade de $8,0 \mathrm{~kg}$ de solo seco por vaso. Resíduos de azevém foram secos em estufa a uma temperatura de $60^{\circ} \mathrm{C}$, até massa constante, e cortados em pedaços de $5 \mathrm{~cm}$. A seguir, foram pesadas porções de 5,0; 10,0; 20,0; 30,0 e 40,0g de resíduos, que corresponderam a doses de 1,$25 ; 2,5 ; 5,0 ; 7,5$ e $10 \mathrm{Mg}$ ha $^{-1}$, respectivamente, que foram aplicadas na superfície do solo. À medida que as amostras de solo foram colocadas nos vasos, os dispositivos de coleta da solução do solo (SOUSA et al., 2002a) foram acomodados na profundidade de $15 \mathrm{~cm}$.

Sementes de arroz da 'cultivar BRS 7’ (Taim) foram pré-germinadas e, quando a radícula apresentou $1 \mathrm{~mm}$ de comprimento, 10 plântulas por balde foram transplantadas na superfície do solo, sendo este mantido com umidade próxima a $18 \%$ de umidade gravimétrica. Após 15 dias, procedeu-se ao alagamento do solo, mantendo-se uma lâmina de água de aproximadamente $5 \mathrm{~cm}$ de altura. Em seguida, ao início do alagamento, foi realizado um desbaste, mantendose quatro plantas por vaso. Após 15 dias de alagamento, foi realizado novo desbaste, mantendo-se duas plantas por vaso, que foram cultivadas até 45 dias de alagamento.

Na solução do solo, foram avaliados o potencial redox (Eh), o pH e as concentrações de $\mathrm{Mn}$, $\mathrm{Fe}, \mathrm{K}, \mathrm{Ca}, \mathrm{Mg}$, conforme metodologia descrita em SOUSA et al. (2002a). Nas plantas de arroz, foram avaliados a massa seca da parte aérea do arroz após secagem em estufa, a $60^{\circ} \mathrm{C}$, e os teores dos nutrientes: N, P, K, Ca, Mg, Fe, Mn, Cu e Zn, segundo métodos descritos em TEDESCO et al. (1995). Os dados foram submetidos à análise de regressão polinomial utilizando o Sistema de Análise Estatística (SANEST). Os valores 
da variável independente (x) corresponderam às doses de resíduos de azevém, e os valores da variável dependente (y), aos indicadores avaliados.

\section{RESULTADOS E DISCUSSÃO}

Houve efeito direto das doses de resíduos de azevém no pH da solução do solo e um efeito inverso para o Eh (Figura 1). Na primeira época de amostragem (15 dias de alagamento), os menores valores de Eh e maiores de $\mathrm{pH}$ foram obtidos com a dose máxima de resíduos de azevém (10Mg ha-1), enquanto que, na segunda época (44 dias), a diminuição nos valores de Eh e o aumento do $\mathrm{pH}$ ocorreram até a dose de $7,5 \mathrm{Mg}$ ha ${ }^{-1}$. O comportamento do Eh e pH são explicados pela intensificação do processo de oxirredução do solo em decorrência da maior disponibilidade de carbono orgânico aos microorganismos anaeróbios (PONNAMPERUMA, 1972). Os efeitos dos resíduos de azevém sobre o Eh e $\mathrm{pH}$ foram mais pronunciados aos 15 dias de alagamento do que aos 44 dias, pois o processo de oxirredução do solo é mais intenso no início do alagamento (SOUSA et al., 2002a). Na segunda época de amostragem, as reações de oxirredução tendem para a estabilidade, e os efeitos dos resíduos sobre o Eh e pH são menores.

As concentrações de manganês na solução do solo aumentaram aos 15 dias e diminuíram aos 44 dias com a aplicação de doses de resíduos de azevém (Figura 2). As concentrações de ferro na solução do solo aumentaram com a aplicação de doses de azevém nas duas épocas de amostragem, principalmente aos 15 dias (Figura 2). As maiores concentrações de manganês $\left(4,1 \mathrm{mg} \mathrm{L}^{-1}\right)$ e ferro $\left(60,5 \mathrm{mg} \mathrm{L}^{-1}\right)$ na solução do solo foram obtidas na dose máxima de resíduos de azevém $\left(10 \mathrm{Mg} \mathrm{ha}^{-1}\right)$ aos 15 dias de alagamento. $\mathrm{O}$ manganês e o ferro sofrem redução microbiana durante o alagamento, e a adição de resíduos vegetais intensifica a atividade microbiana, aumentando a redução desses elementos e a liberação para a solução do solo (PONNAMPERUMA, 1972).

Os maiores efeitos dos resíduos de azevém, nas concentrações de manganês, em Planossolos, ocorreram apenas nas quatro primeiras semanas de alagamento, não sendo possível distinguir diferenças entre tratamentos a partir dos 41 dias (SOUSA, 2001). Segundo MADRUGA (1999) e SOUSA (2001), os resíduos vegetais alteram a dinâmica inicial da redução do solo e no máximo de liberação dos elementos, mas interferem muito pouco nas concentrações finais de equilíbrio.

Os resíduos de azevém proporcionaram maiores teores de cálcio e magnésio na solução do solo, e as maiores concentrações desses elementos (203,9mg L ${ }^{-1}$ de Ca e 42,3mg L L $^{-1}$ de Mg) ocorreram com a dose de $10 \mathrm{Mg} \mathrm{ha}^{-1}$ de resíduos. O aumento na concentração de cálcio e magnésio ocorreu devido ao deslocamento desses cátions dos sítios de troca pelo ferro e manganês (PONNAMPERUMA, 1972) e também devido à liberação de uma parcela hidrossolúvel desses elementos dos resíduos de azevém. Segundo MARSCHNER (1995), embora a maior parte do cálcio nos tecidos vegetais encontre-se fortemente ligada a sítios específicos na parede celular, uma parcela de 20 a 30\% é solúvel em água. Para o magnésio, segundo o mesmo autor, entre 60 e $90 \%$ do elemento presente no tecido vegetal é solúvel em água, podendo ser rapidamente liberado de resíduos vegetais para o solo.

As concentrações de potássio na solução do solo aumentaram com a adição dos resíduos de azevém na superfície do solo, atingindo as maiores concentrações (26,2mg L-1 de K) na dose de $10 \mathrm{Mg} \mathrm{ha}^{-1}$, aos 15 dias de alagamento. O potássio, embora não
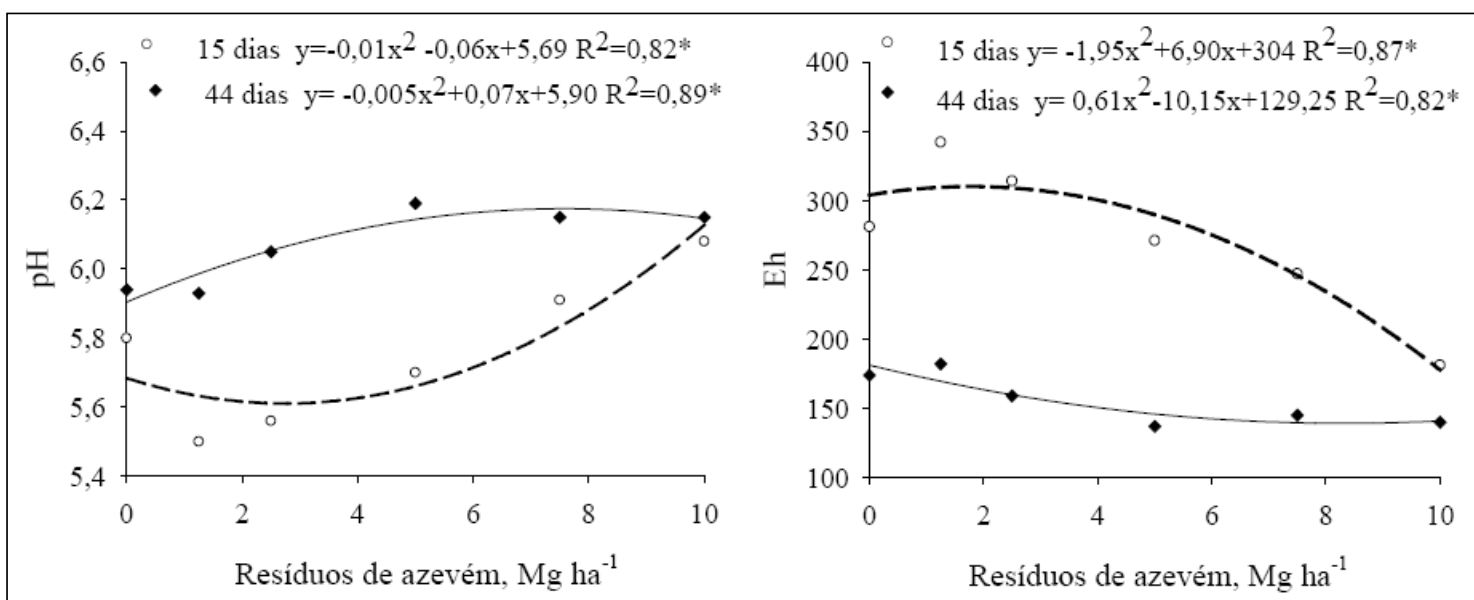

Figura 1 - pH e Eh da solução do solo em função de doses de resíduos de azevém aos 15 e 44 dias de alagamento. * Nível de significância $5 \%$. 

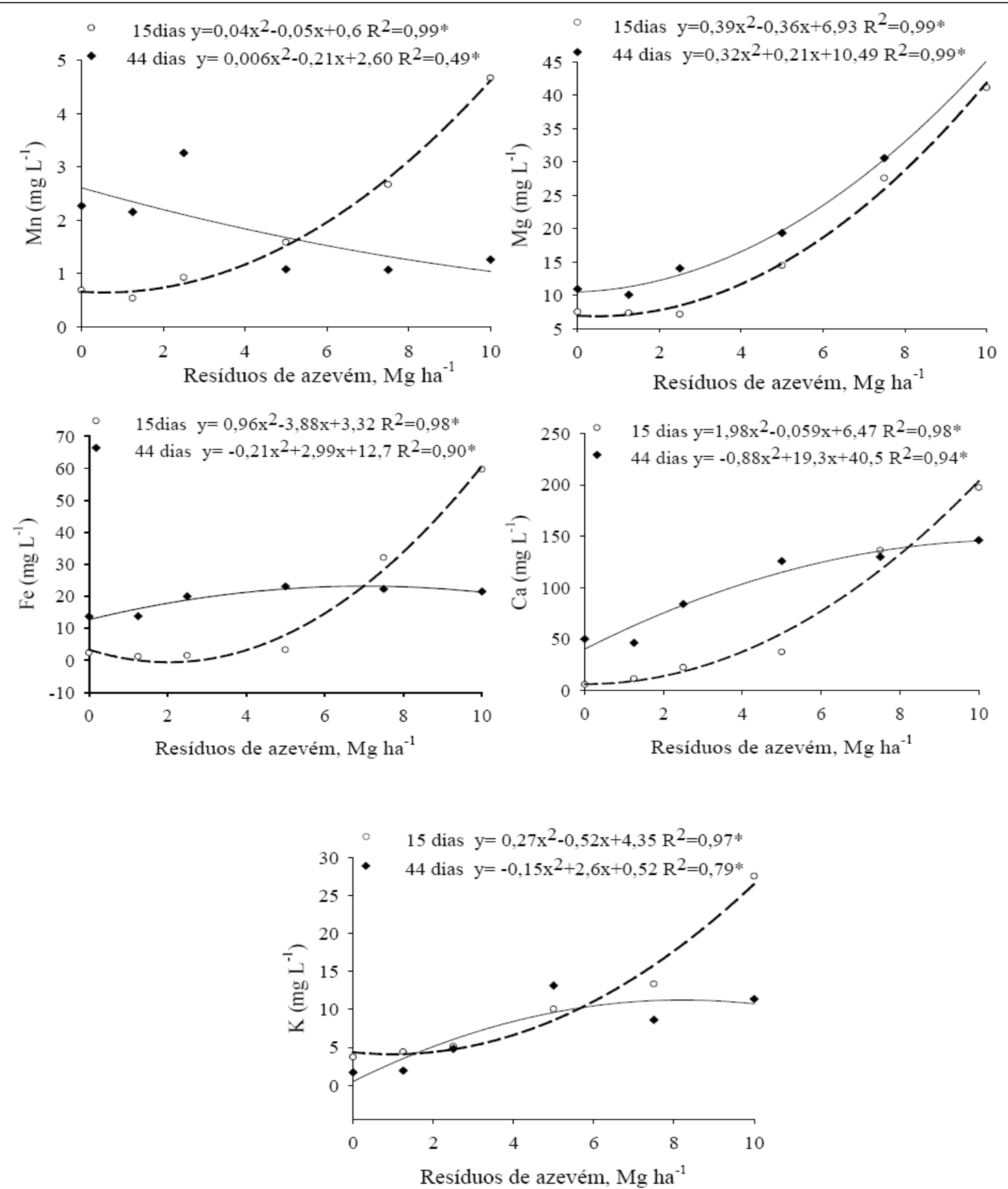

Figura 2 - Concentração de Mn, Fe, Ca, Mg, e K na solução do solo, em função de doses de resíduos de azevém aos 15 e 44 dias de alagamento. * Nível de significância 5\%.

participando diretamente das reações de oxirredução, é deslocado dos sítios de troca pelo ferro e manganês, sendo ainda, facilmente liberado de resíduos vegetais para o solo. O potássio encontra-se no interior da planta na forma iônica, podendo ser extraído de resíduos vegetais apenas com a umidade do solo, sem necessitar da interferência da atividade microbiana, pois o potássio não é metabolizado no interior da planta e forma complexos fracos que são facilmente trocáveis (MARSCHNER, 1995).

A massa seca da parte aérea do arroz aumentou com as doses crescentes de resíduos de azevém, atingindo os maiores valores $\left(9,6 \mathrm{~g} \mathrm{vaso}^{-1}\right)$ na dose máxima de $10 \mathrm{Mg} \mathrm{ha}^{-1}$ (Figura 3). A maior 


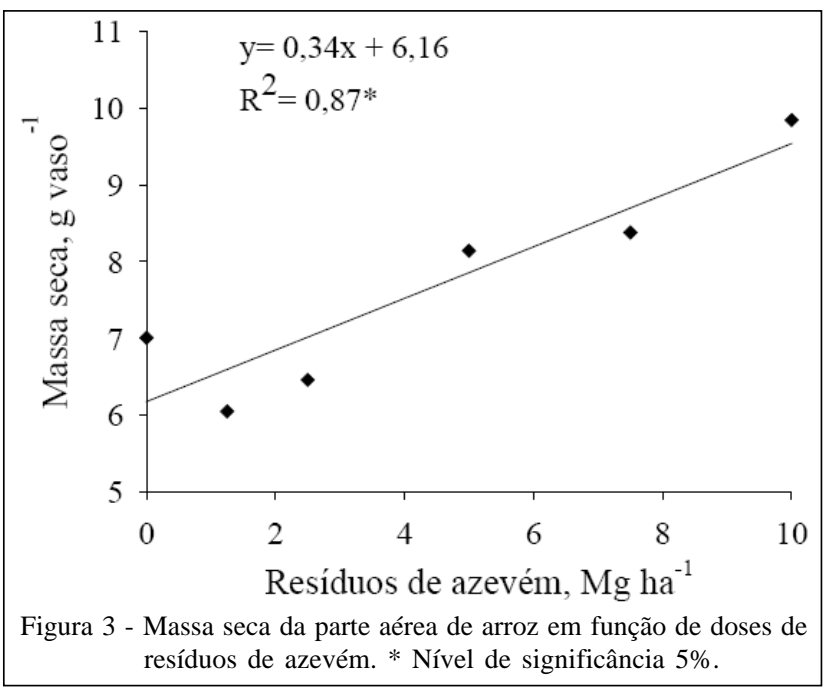

disponibilidade de nutrientes no solo, em decorrência dos resíduos na superfície, favoreceu a nutrição do arroz, que respondeu com maior produção de matéria seca. O efeito negativo de produtos liberados pelo metabolismo anaeróbio não foi observado na massa seca das plantas. Como os resíduos foram colocados na superfície, é provável que as raízes, ao aprofundarem no solo, atingiram regiões com concentrações baixas de ácidos orgânicos mesmo nas doses mais altas de resíduos, pois os ácidos apresentam baixa capacidade de difusão no solo. LYNCH et al. (1980) observaram que as concentrações de ácido acético diminuíram em $50 \%$, a uma distância de $1,5 \mathrm{~cm}$ de resíduos de cevada e de $1,65 \mathrm{~cm}$ de resíduos de trigo, sob condições anaeróbias. Além disso, a produção de ácidos orgânicos é muito menor quando os resíduos são deixados na superfície em comparação com a incorporação destes no solo (SOUSA et al., 2002b).

Os teores de nitrogênio, fósforo e cálcio, na parte aérea do arroz, não foram afetados pelos resíduos de azevém, enquanto que houve aumento nos teores de potássio e diminuição nos teores de magnésio (Tabela 1). Normalmente a aplicação de resíduos vegetais aumenta a disponibilidade desses elementos no solo, pela intensificação da atividade microbiana ou pela liberação direta de nutrientes dos resíduos, e as plantas são beneficiadas com uma maior absorção (SOUSA, 2001). É provável que tal benefício não tenha se manifestado para alguns elementos por efeito de diluição, devido ao aumento da massa seca. O aumento nos teores de potássio ocorreu pela maior liberação do elemento dos resíduos de azevém (Figura 2), como já foi discutido anteriormente.

Os teores de ferro na parte aérea do arroz aumentaram com o aumento das doses de resíduos de azevém, atingindo os maiores teores (267,2mg kg ${ }^{-1}$ de Fe) na dose de 10,0Mg ha-1 (Figura 4), provavelmente devido à maior concentração de ferro na solução (Figura 2). Com três semanas de alagamento, as plantas apresentaram sintomas típicos de toxidez por ferro nas doses $7,5 \mathrm{Mg} \mathrm{ha}^{-1}$ e $10,0 \mathrm{Mg} \mathrm{ha}^{-1}$ de resíduos de azevém. Os sintomas se manifestaram por um curto período de tempo, e as plantas já não apresentavam nenhum sintoma próximo à época de amostragem. Os sintomas ocorreram entre a segunda e a terceira semana de alagamento, quando os teores de ferro foram superiores a $300 \mathrm{mg} \mathrm{kg}^{-1}$ (dados não apresentados), que, segundo YOSHIDA (1981), é o nível crítico de toxidez do elemento na parte aérea do arroz.

Os teores de manganês e zinco na parte aérea do arroz diminuíram com o aumento das doses de resíduos de azevém (Figura 4). Os menores teores de manganês (183,0 $\mathrm{mg} \mathrm{kg}^{-1}$ ) ocorreram com a adição de 10,0 $\mathrm{Mg} \mathrm{ha}^{-1}$ de resíduos, enquanto que, para o zinco,

Tabela 1 - Teores de macronutrientes na parte aérea do arroz, em função de doses de resíduos de azevém.

\begin{tabular}{|c|c|c|c|c|c|}
\hline Resíduos de azevém (Mg ha ${ }^{-1}$ ) & $\mathrm{N}$ & $\mathrm{P}$ & $\begin{array}{c}\mathrm{K} \\
--\mathrm{g} \mathrm{kg}^{-1}--\end{array}$ & $\mathrm{Ca}$ & $\mathrm{Mg}$ \\
\hline 0,00 & $22,04^{\text {ns }}$ & $3,66^{\text {ns }}$ & $18,40^{1 *}$ & $1,81^{\mathrm{ns}}$ & $1,90^{2^{*}}$ \\
\hline 1,25 & $28,02^{\mathrm{ns}}$ & $3,47^{\mathrm{ns}}$ & $20,13^{1^{*}}$ & $2,15^{\mathrm{ns}}$ & $1,71^{2^{*}}$ \\
\hline 2,50 & $30,90^{\mathrm{ns}}$ & $3,60^{\mathrm{ns}}$ & $21,78^{1^{*}}$ & $2,03^{\text {ns }}$ & $1,50^{2^{*}}$ \\
\hline 5,00 & $25,79^{\mathrm{ns}}$ & $3,57^{\mathrm{ns}}$ & $21,31^{1^{*}}$ & $1,89^{\text {ns }}$ & $1,66^{2^{*}}$ \\
\hline 7,50 & $27,37^{\text {ns }}$ & $3,63^{\text {ns }}$ & $24,06^{1^{*}}$ & $2,03^{\text {ns }}$ & $1,50^{2^{*}}$ \\
\hline 10,0 & $26,99^{\mathrm{ns}}$ & $3,23^{\mathrm{ns}}$ & $23,98^{1^{*}}$ & $2,07^{\mathrm{ns}}$ & $1,54^{2^{*}}$ \\
\hline
\end{tabular}

\footnotetext{
* Nível de significância 5\%.

${ }^{1} \mathrm{y}=0,5275 \mathrm{x}+19,3, \mathrm{R}^{2}=0,85^{*}$

${ }^{2} \mathrm{y}=0,007 \mathrm{x}^{2}-0,096 \mathrm{x}+1,84, \mathrm{R}^{2}=0,69 *$

ns $=$ não significativo.
}

Ciência Rural, v.39, n.7, out, 2009. 

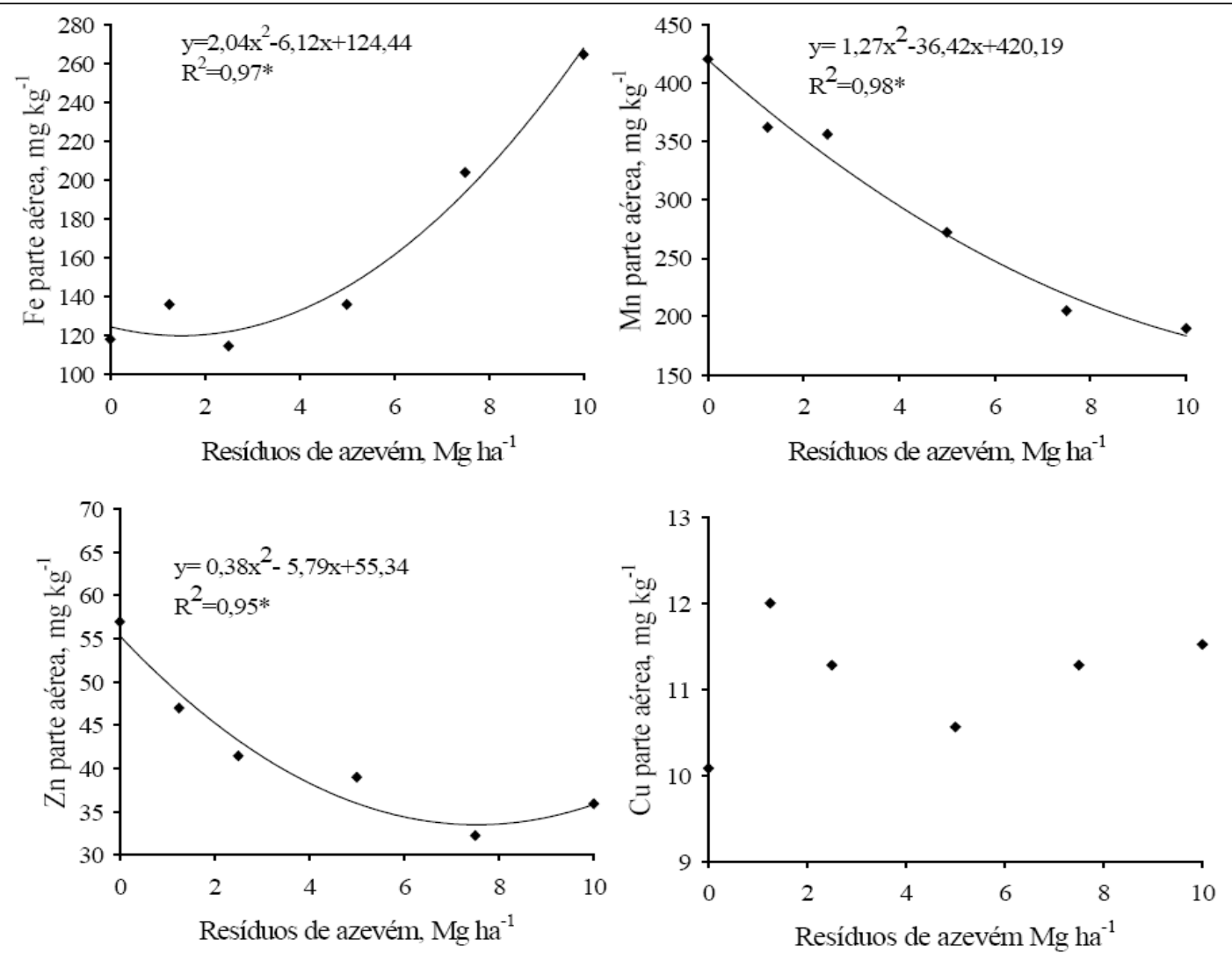

Figura 4 - Teores de micronutrientes na parte aérea de plantas de arroz, em função de doses de resíduos de azevém. * Nível de significância $5 \%$.

os menores teores (33,3mg kg-1) ocorreram com 7,5Mg ha $^{-1}$ de resíduos. O aumento nos teores de manganês, na solução do solo, ocorreu apenas na primeira época de amostragem, e os teores na solução foram baixos (Figura 2). As quantidades de manganês liberadas para a solução do solo foram cerca de 100 vezes menores do que as concentrações de ferro. Assim, é provável que a menor quantidade de manganês na parte aérea do arroz tenha sido causada por efeito inibitório do ferro na absorção do manganês e/ou por efeito de diluição devido ao aumento de massa seca. Os menores teores de zinco na parte aérea podem ter ocorrido pela diminuição de sua disponibilidade devido ao aumento do $\mathrm{pH}$, que faz com que esse micronutriente fique mais fortemente adsorvido na fase sólida, formando complexos de superfície (Mc BRIDE, 1994).

Os teores de cobre na parte aérea do arroz não apresentaram relação com as doses de resíduos de azevém (Figura 4). O cobre é mais adsorvido com o aumento do $\mathrm{pH}$ (Mc BRIDE,1994), assim como ocorre com o zinco, porém isso não resultou em menor absorção do elemento. Outro aspecto que pode ter contribuído para a diminuição dos teores de magnésio
(Tabela 1), manganês e zinco (Figura 4), na parte aérea do arroz, refere-se ao aumento dos teores de ferro na solução do solo e sua absorção pelas plantas que afetam significativamente a nutrição do arroz. Essa interferência é particularmente importante para os cátions divalentes, tais como $\mathrm{Ca}, \mathrm{Mg}, \mathrm{Mn}, \mathrm{Zn}$ e $\mathrm{Cu}$, os quais têm a absorção diminuída com a presença de altos teores de ferro em solução (VAHL, 1991).

\section{CONCLUSÕES}

As concentrações de $\mathrm{Mn}, \mathrm{Fe}$, Ca e $\mathrm{K}$ na solução do solo aumentam com a adição de resíduos de azevém na superfície de um Planossolo alagado até a dose máxima utilizada de $10 \mathrm{Mg} \mathrm{ha}^{-1}$. Os teores de $\mathrm{Fe}$ e K na parte aérea do arroz aumentam, e os de Mn, Zn e Mg diminuem com a adição de resíduos de azevém na superfície de um Planossolo alagado até a dose máxima de10Mg ha-1 . A produção de massa seca da parte aérea do arroz aumenta com a adição de doses crescentes de resíduos de azevém na superfície de um Planossolo alagado até a dose máxima de10Mg ha-1. 


\section{REFERÊNCIAS}

GAO, S. et al. Impact of rice straw incorporation on soil redox status and sulfide toxicity. Agronomy Journal, Madison, v.96, p.70-76, 2004. Disponível em: http:// agron.scijournals.org/cgi/content/abstract/96/1/70. Acesso em: 05 maio. 2009.

GOMES, A.S. et al. Plantio direto e cultivo mínimo em arroz irrigado. In: GOMES, A.S.; MAGALHÃES JR, A.M. (Eds.). Arroz irrigado no Sul do Brasil. Brasília: EMBRAPA Informação Tecnológica, 2004. p.349-383.

IRGA - Censo da Lavoura de Arroz Irrigado do Rio Grande do Sul - safra 2004/5. Porto Alegre, IRGA, 2006. 122p.

LYNCH, J.M. et al. On the concentration of acetic acid in straw and soil. Plant and soil, The Hague, v.56, p.93-98, 1980. Disponível em: http://www.springerlink.com/content/ u422qh0576156262/. Acesso em: 05 maio. 2009. doi: 10.1007/ BF02197956.

MADRUGA, E.F. Efeito da aplicação de resíduo vegetal e nitrato sobre a redução do solo. 1999. 47f. Dissertação (Mestrado em Solos) - Faculdade de Agronomia, Universidade Federal Pelotas, Pelotas, RS.

MARSCHNER, H. Mineral nutrition of higher plants. London: Academic, 1995. 889p.

Mc BRIDE, M.B. Environmental chemistry of soils. New York: Oxford University, 1994. 406p.

MENEZES, V.G. et al. Efeito de espécies de inverno sobre cultivares de arroz irrigado em semeadura direta. In: REUNIÃO DA CULTURA DO ARROZ IRRIGADO, 22., 1997, Camboriú. Anais... Itajaí: EPAGRI, 1997. p.177-179.
PONNAMPERUMA, F.N. The chemistry of submerged soils. Advances in Agronomy, New York, v.24, p.29-96, 1972.

SINGH, Y. et al. Efficient management of leguminous green manures in wetland rice. Advances in Agronomy, New York, v.45, p.135-189, 1991.

SOUSA, R.O. et al. Composição da solução de um solo alagado conforme a profundidade e o tempo de alagamento, utilizando novo método de coleta. Revista Brasileira de Ciência do Solo, Campinas, v.26, p.343-348, 2002a.

SOUSA, R.O. et al. Short chain organic acid dynamics in solution of flooded soil treated with ryegrass residues. Communications in Soil Science and Plant Analysis. Athens, v.33, n.5 e 6, p.779-787, 2002b. Disponível em: http://www.informaworld.com/ smpp/content $\sim$ content $=\mathrm{a} 713623850 \sim \mathrm{db}=$ all $\sim$ order $=$ page. Acesso em: 05 maio. 2009. doi: 10.1081/CSS-120003065.

SOUSA, R.O. Oxirredução em solos alagados afetada por resíduos vegetais. 2001. 164f. Tese (Doutorado em Ciência do Solo) - Faculdade de Agronomia, Universidade Federal do Rio Grande do Sul, Porto Alegre, RS.

TEDESCO, M.J. et al. Análise de solo, plantas e outros materiais. 2.ed. Porto Alegre: Departamento de Solos da UFRGS, 1995. 174p. (Boletim Técnico de Solos, 5).

VAHL, L.C. Toxidez de ferro em genótipos de arroz irrigado por alagamento. 1991. 167f. Tese (Doutorado em Ciência do Solo) - Faculdade de Agronomia, Universidade Federal do Rio Grande do Sul, Porto Alegre, RS.

YOSHIDA, T. Fundamentals of rice crop science. Los Baños: IRRI, 1981. 269p. 